ELORE (ISSN 1456-3010), vol. 19 - 1/2012.

Julkaisija: Suomen Kansantietouden Tutkijain Seura ry.

[http://www.elore.fi/arkisto/1_12/suutari.pdf]

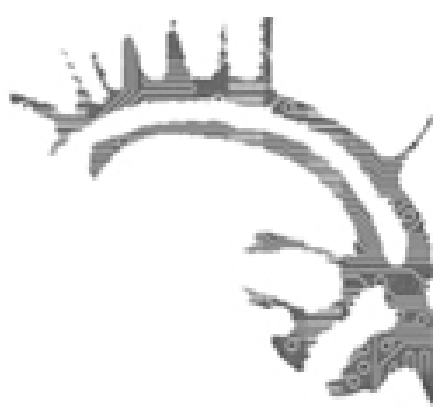

Kolumni

\title{
HEIKKONEN ON SUKUPOLVIKOKEMUS VENÄJÄLLÄ
}

\section{$\underline{\text { Pekka Suutari }}$}

Vietin syksyn 2011 kenttätöissä ja vierailevana tutkijana Petroskoissa - suomalaisten myyttisenä pitämässä Karjalassa. Meillä, Itä-Suomen yliopiston Karjalan tutkimuslaitoksella ja Venäjän tiedeakatemian Karjalan tiedekeskuksella, on yhteinen Joustavat etnisyydet -hanke, jonka tarkoituksena on tarkastella Petroskoin ja lähiympäristön nykykulttuuria ja erityisesti kysymystä siitä, miten etnisyydet ovat nykyään toisiinsa limittyviä, päällekkäisiä ja toiminnallisia. Kun tarkastelemme moni-identtisyyttä, on etsittävä kohtia, joissa kertomukset kansallisista historioista tulevat näkyviin nykypäivässä. ${ }^{1}$

Trebljankan esikaupungissa sijaitseva yöklubi Heikkonen ei ole niitä tyypillisimpiä kohteita, kun etsitään kansallisesti merkittäviä kulttuurimuotoja Karjalasta. Yhtä kaikki sukupolvikokemuksena ja vaihtoehtoisen taiteen ja kulttuuritodellisuuden mahdollistajana se on kuitenkin tärkeä paikka, jossa valtavirrasta poikkeavat musiikkikulttuurit pääsevät esiin. Kun ystäväni houkuttelivat minua sinne kertomalla, että se on nuorille paitsi kulttuurisesti myös sosiaalipoliittisesti tärkeä paikka, oli helppo tarttua kutsuun ja suunnata myöhään lauantai-iltana taksin takapenkillä kohti Heikkosta.

Heikkonen-klubi on toiminut osoitteessa Ulitsa Heikkonena 39 noin kolme vuotta, ja sen tärkeimpänä missiona on tuoda vaihtoehtoisia undergroundia edustavia musiikkikulttuureja esiin Karjalassa. Paikan nimi oli aiemmin Porshen, mutta nyt uusittuna katuosoitteensa mukaisesti Heikkonen. Klubin toiminta perustuu pitkälti vapaaehtoisuuteen ja se onkin auki vain viikonloppuisin; perjantaisin klo 20-03 ja 


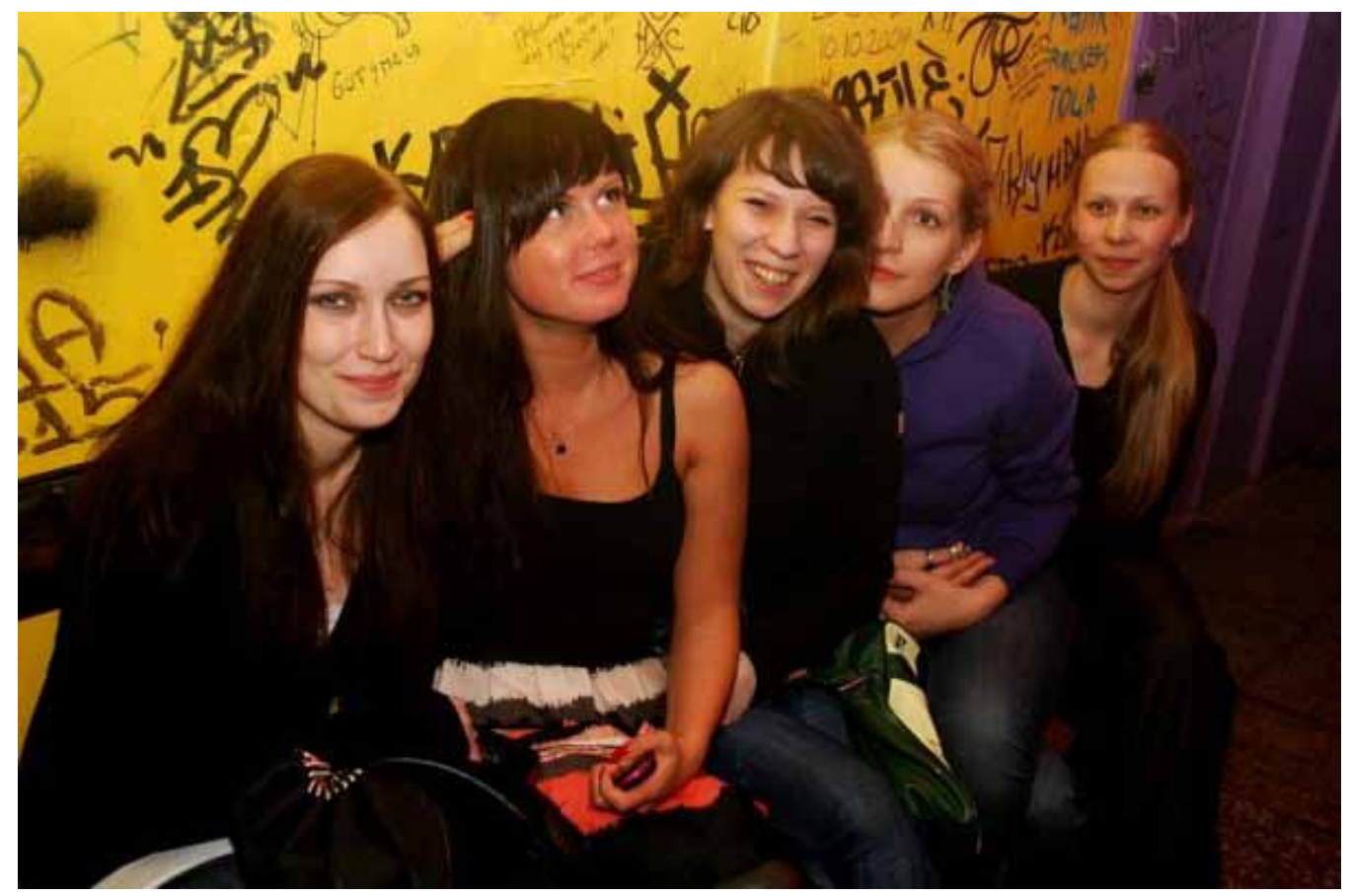

Heikkonen-yöklubin nuorta petroskoilaista yleisöä. Kuva: Arkadi Sokolovin arkisto.

lauantaisin 23-06. Toiminnasta tarkemmin minulle kertoi Arkadi Sokolov, joka on paitsi Heikkosen aktiivitoimija myös Asketics-yhtyeen rumpali.

Jokaisella illalla on Heikkosessa omat teemansa, kuten hip hop, dubstep, punk, electro, metal ja techno mafia, ja niitä mainostetaan tyylikkäillä grafiikkataidetta edustavilla julisteilla. Olennaisesti Heikkonen on myös Internet-yhteisö. Facebookia vastaavassa venäläisessä Vkontaktessa klubilla on noin 3000 jäsentä, ja kutsut iltoihin tulevat myös henkilökohtaisesti. Yleisöä paikkaan mahtuu kuitenkin vain ehkä 200-250. Periaatteessa klubiin voi järjestää omankin konsertin ja mikä parasta klubin kanta-asiakkaat seikkailevat hyvin monenlaisen underground-musiikin maailmoissa. Tunnelma on vähintäänkin avarakatseinen ja luova.

Heikkonen klubilla on aina sekä live-musiikkia että DJ, ja klubin vetäjät itsekin ovat muusikoita, DJ:tä ja taiteilijoita. Paikan etuna onkin erinomainen musiikkitarjonta, laadukas soundi ja kiinteät musiikkilaitteet. Kuvataiteiden merkitys Heikkosessa on myös suuri: seinillä on vaihtuvia näyttelyjä ja videoscreenillä korkeatasoisesti toteutettuja installaatioita. Vaikka klubi on rakennettu karuun betonilaatikkoon ja sisustus on yksinkertainen, antavat varsinkin videoinstallaatiot sille monitahoisia merkityksiä. Videotaiteen Heikkoseen tekee Aleksandr Fartushnyj. Kuvitus abstrakteine henkilöhahmoineen sekä videoissa liikkuva leikki graafisilla hahmoilla ja väreillä vangitsevat katseen ja antavat mielikuvitukselle vauhtia.

Heikkonen toimii enemmän yöllä kuin valoisaan aikaan. Silti koko paikan asenne nuorille tarjottavaan klubikulttuuriin on huolehtivan vaihtoehtoinen. Sisällä tupakointi 


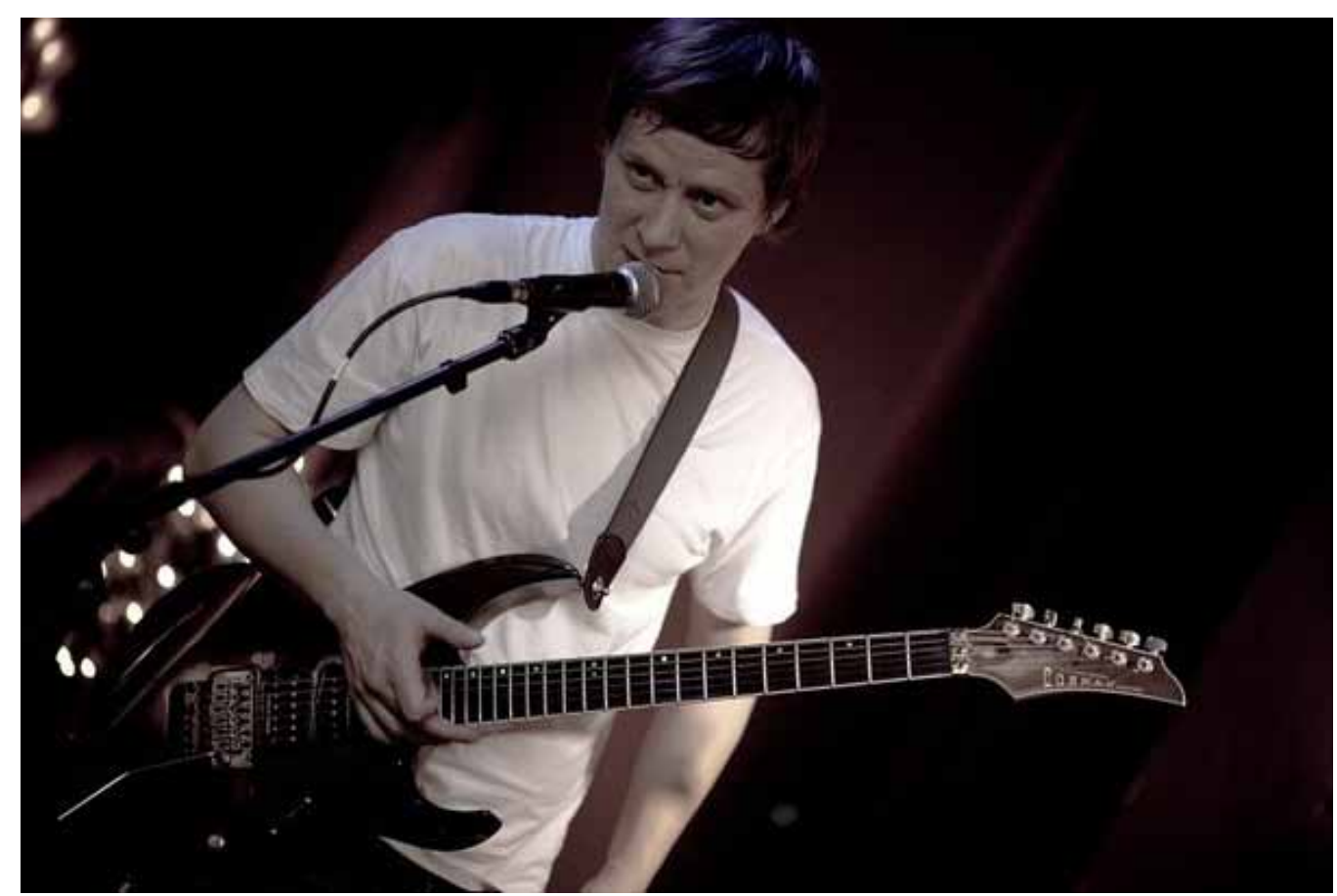

Klubin vetäjien oma yhtye on musiikinlajien rajamaastossa liikkuva trio Asketics. Kuva: Arkadi Sokolovin arkisto.

on kiellettyä, mutta takapihalla on nuotio, jonka äärellä on paljon väkeä lämmittelemässä pakkasilmassa. Tässä suhteessa Heikkosella on etuakin syrjäisestä sijainnista kaukana kaupungin keskustasta. Heikkosessa järjestetään myös säännöllisesti joogailtoja. Vaikka Heikkonen ei ole mikään terveysintoilun paikka, kirkas mieli korostuu paikan ideologiassa. Baaritiskin lisäksi tarjolla on teehuone, jossa tutustuminen toisiin ihmisiin on helppoa.

Ystäväni Irina Smirnova selittää, että nuori sukupolvi tarvitsee nykyään henkilökohtaisuutta ja kohtaamisia toisten ihmisten kanssa. Jos yhteiskunta ympärillä on muuttunut yhä individualistisemmaksi ja itsekkäämmäksi, ihmiset tarvitsevat entistäkin kipeämmin paikkaa luoda vaihtoehtoisen yhteisöllisyyden malleja. Heikkosen tapauksessa tämä yhteisöllisyyden luominen tapahtuu musiikin avulla. Irina kuvaa tuttavaansa Andreita, 25, jolle elämä on kivikkoista, suhteet vanhempiin ovat hankalat ja tyttöystävän kanssa on kitkaa. Jos vanhemmat pyrkivät määräilemään ja muilla ystävillä ei ole aikaa, Irina selittää, musiikki on Andreille kuin hyvä ystävä, joka kommunikoi ja välittää tunteista.

Ilta, jona kävimme Heikkosessa, oli omistettu Electro Dubille. Bändejä on kaksi, ja lisäksi klubilla esiintyi kolme DJ:tä. Ensiksi esiintyi DJ, joka väänteli napeistaan äänen aalto-ominaisuuksia, kuin Erkki Kurenniemi omista syntikoistaan 1960-luvun lopulla Helsingissä. Kyse ei ollut siis kappaleiden soittamisesta vaan rakentamisesta ääniä syntetisoimalla ja muokkaamalla. Ensimmäinen paikallinen bändi esiintyi 
Pekka Suutari: Heikkonen on sukupolvikokemus Venäjällä

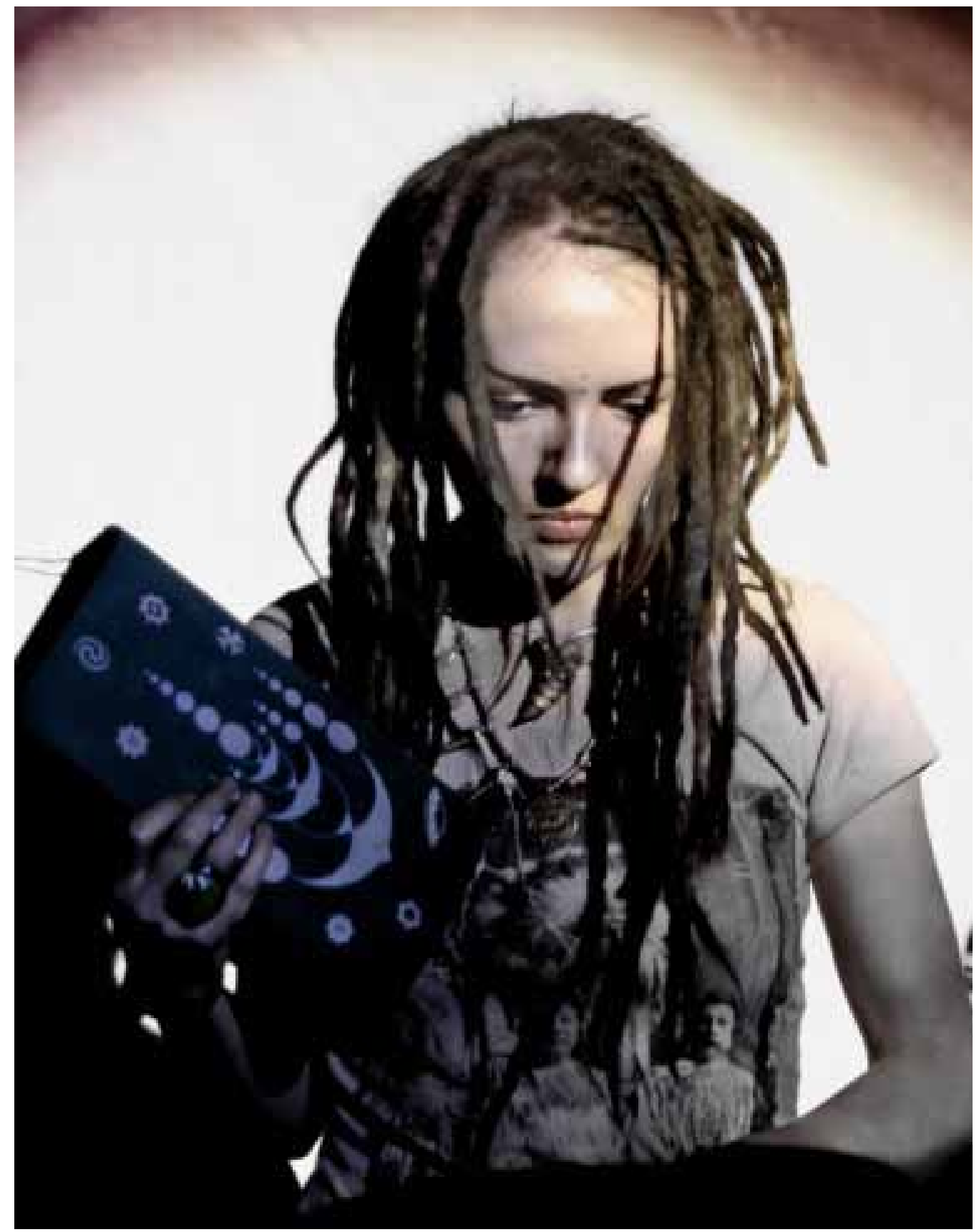

Dj Milita Rastan työkaluina ovat levysoitin ja miksauspöytä. Kuva: Arkadi Sokolovin arkisto. 
kokoonpanossa kitara, trumpetti, basso, DJ ja tietokone. Siinä varsinkin trumpetin äänet toivat syvyyttä koneiden tekemään musiikkiin. Illan pääesiintyjä oli Pietarista saapunut ryhmä nimeltä Electro Dub Company. Sen vetäjä oli kahta kosketinsoitinta käyttänyt DJ Milita rasta (oikealta nimeltään Marina), ja mukana oli lisäksi basso ja rummut sekä Marinan mies yhtyeen kitaristina. Basso jyräsi erittäin kovaa, koskettimet lähinnä koristelivat ja rumpusetti oli sekin aika lailla taustalla. Milita rasta on harvoja naispuolisia DJ:tä tässä genressä. Hän veti ohjelmaa luoden katsekontaktia yleisöön suuren tukkansa alta ja esiintyi myös yksin DJ:nä ennen bändin osuutta. Electro-dub skene on suurta Venäjällä ja muualla, mutta Milita rastalla ei valitettavasti ole ollut keikkoja Suomessa. Pietarissa keikkoja on usein eikä hän ollut ensimmäistä kertaa Petroskoissakaan esiintymässä.

Venäjän nuoren sukupolven keskuudessa on kova kiire kohti menestystä. Aikaa oman minän kehitykselle ja erilaisten asioiden kokemiselle ystävien kanssa ei tahdo olla. Vaihtoehtoisen musiikin ja samalla maailmankuvan etsimiselle on kuitenkin tilaa. On hienoa nähdä, miten vahvasti Heikkonen toimii ja miten helposti lähestyttävä henki paikassa on. Keskusteluja oli helppo synnyttää niin muusikoiden kuin paikan vetäjien ja nuorten asiakkaidenkin kanssa. Seuraava käyntini Heikkosessa tulee olemaan Nuori Karjala -järjestön etnoillatšu Lembi huhtikuun lopulla 2012. Sillä kertaa otan kyllä kunnolliset korvatulpat mukaan, sen verran äänekästä paikan musiikki on.

Heikkonen club

Ul. Heikkonena 39

+79114010844

zadpop@yandex.ru

\section{VIITE}

1 Tarkemmat tiedot löytyvät Flexible Ethnicities -hankeen Internet sivulta osoitteesta <http://www.uef.fi/fe> [15.4.2012.]

Pekka Suutari on etnomusikologi ja kulttuurintutkimuksen professori Karjalan tutkimuslaitoksella, Itä-Suomen yliopistossa sekä Karjalan tutkimuslaitoksen johtaja. Hän vetää Suomen Akatemian rahoittamaa hanketta Joustavat etnisyydet, jossa on mukana myös Venäjän Tiedeakatemian Karjalan tiedekeskus. 